\title{
A norovirus outbreak triggered by copper intoxication on a coach trip from the Netherlands to Germany, April 2010
}

J Hoefnagel (jhoefnagel@ggd-nijmegen.nl) ${ }^{1}$, D H van de Weerdt ${ }^{2}, 0$ Schaefer ${ }^{3}$, R Koene $^{1}$

1. Department of Infectious Diseases, Public Health Service (GGD) Nijmegen, Nijmegen, the Netherlands

2. Environmental Health Unit, Public Health Service (GGD Gelderland-Midden) Arnhem, Arnhem, the Netherlands

3. Department of Public Health and Infectious Disease Control, Public Health Service Hochsauerlandkreis, Meschede, Germany

Hoefnagel J, van de Weerdt DH, Schaefer O, Koene R. A norovirus outbreak triggered by copper intoxication on a coach trip from the Netherlands to Germany, April 2010.

Euro Surveill. 2012;17(9):pii=20104. Available online: http://www.eurosurveillance.org/ViewArticle.aspx?Articleld=20104

We report an unusual outbreak of norovirus infection on a coach trip. Overall, 30 of 40 people (including drivers and crew) developed nausea, vomiting and/or diarrhoea, 11 of them on the first day of the trip. The incidence epidemic curve showed a first peak on Day 1 and a second on Day 4. Nine passengers were hospitalised with gastrointestinal symptoms. Norovirus was found in stool samples from two patients, but the infection could not explain the first peak in the epidemic curve only a few hours after departure. Interviews with the passengers and an inspection of the coach and its water supply implicated the water used for coffee and tea as the potential source. Microbiological investigations of the water were negative, but chemical analysis showed a toxic concentration of copper. Blood copper levels as well as renal and liver function were determined in $\mathbf{2 8}$ of the $\mathbf{3 2}$ passengers who had been exposed to the water. One passenger who did not have gastrointestinal symptoms had an elevated copper level of $25.9 \mu \mathrm{mol} / \mathrm{L}$, without loss of liver or renal function. It is likely that the spread of norovirus was enhanced because of vomiting of one of the passengers due to copper intoxication.

\section{Introduction}

Noroviruses are RNA viruses that belong to the family of Caliciviridae. The viruses are highly infectious and cause gastroenteritis in humans. Transmission can easily occur through consumption of contaminated food or water, through contact with people shedding the virus or through contaminated aerosols resulting from vomiting [1]. Attack rates are high, and outbreaks are seen among large groups of people, as in nursing homes for the elderly, day nurseries, hospitals and restaurants. Noroviruses are also a well known cause of acute gastroenteritis on cruise ships [2] and among coach passengers [3].

In April 2010, the Dutch Public Health Service (PHS) of Nijmegen was informed by the German PHS of
Hochsauerlandkreis that an outbreak of vomiting and diarrhoea was occurring among elderly people on a five-day coach trip from the Netherlands to Sauerland, Germany. The symptoms started a few hours after departure. Stool samples of two patients who were admitted to hospital were found positive for norovirus. However, the incubation period of a norovirus infection is 10 to 72 hours [4], while the symptoms in these passengers started only a few hours after departure. Therefore, norovirus alone did not explain this outbreak, and further investigation was warranted.

\section{Outbreak description}

On Day 1, the coach with 34 passengers, four crew members and one driver, departed at $10.15 \mathrm{am}$. The majority of the passengers were female and 70 to 95 years-old, with an average age of 80 years. Except for married couples (twelve passengers), none of the passengers had had contact with other passengers before the trip.

At $12.15 \mathrm{am}$, coffee and tea was made using a hot water boiler in the coach. Someone noticed that the water had a blue colour. The first pot of hot water was shared by six persons who did not get sick on Day 1 . The second pot was shared by 26 persons, one of whom started vomiting 10 minutes later. By $1.00 \mathrm{pm}, 10$ people were sick and had vomited; one person became sick later that day. Two hours later the coach arrived at the hotel, where people started having diarrhoea. Of the 11 passengers who had symptoms on the first day, only six had diarrhoea. The other five reported nausea and/ or vomiting. From Day 2 to Day 7, 19 more people got sick, including a second driver who replaced the first driver to drive the coach back from Hochsauerland. 16 of them also had diarrhoea.

All nine passengers admitted to a hospital were treated for norovirus infection and/or dehydration, mostly without laboratory confirmation of norovirus. One of them 
was admitted to the intensive care unit for a few days, because of (pre-existing) renal failure and hypokalaemia, probably induced by the diarrhoea.

On Day 4, all 24 passengers who were recovered or healthy returned to the Netherlands with the same coach and a new driver. This driver reported symptoms one day later. The remaining 14 sick passengers were repatriated on Day 6.

\section{Methods}

We conducted a cohort study among a defined and closed population, consisting of all bus passengers, crew members and the drivers. A probable case was defined as a passenger of the coach trip to Germany, including crew and driver, who developed one or more of the following symptoms within eight days after the start of the trip: nausea, stomach pain, vomiting and/ or diarrhoea. A confirmed case was defined as a probable case with laboratory confirmation of norovirus. We interviewed the passengers and performed microbiological analyses of stool samples of three passengers, chemical blood analyses of passengers exposed to boiler water, and chemical environmental analysis on boiler water of the coach.

\section{Interviews with cases}

On Day 4, the PHS of Hochsauerlandkreis was notified about the outbreak by the local hospital. The environmental health officers of the German PHS interviewed the members of the crew and three patients at the hotel where they were staying. To further investigate the outbreak, public health nurses of the PHS of Nijmegen interviewed all passengers and the crew by telephone questionnaire [5], from Day 5 until Day 13 of the outbreak. They were asked about the consumption of food and drinks during the trip, how much coffee they had had, where they were seated in the coach, which symptoms they developed and when these started, whether they had any underlying illnesses, and if they were admitted to a hospital during the trip.

Inspection of the coach

The PHS of Hochsauerlandkreis inspected the coach and interviewed the driver after they were informed about the blue colour of the water during the initial interviews. A further thorough inspection of the coach's water supply was carried out after it had returned to Nijmegen by a medical officer of the PHS of Nijmegen.

\section{Chemical analysis and microbiological} testing of boiler water

A sample of boiler water from the coach was subjected to chemical and microbiological tests. The $\mathrm{pH}$ was determined electrochemically. Chemical tests for organic and inorganic compounds were performed by the Environmental Accident Service (MOD) of the National institute for public health and the environment (RIVM) using gas chromatography-mass spectrophotometry and X-ray fluorescent (XRF) analysis. The sample was cultured on blood agar for Staphylococcus aureus and Bacillus spp., since these bacteria are known to produce toxins that can cause abdominal symptoms a short time after exposure $[6,7]$.

\section{Virological testing of stool samples}

The German hospital tested eight patients (Day 4) and the Dutch PHS tested three patients (Day 6) for norovirus by PCR $[8,9]$. The Dutch PHS also tested for adenovirus and rotavirus by antigen detection (enzyme immunoassay RIDA QUICK Rotavirus/Adenovirus combi, R-Biopharm) and PCR.

\section{Results}

Interviews of the cases

The PHS of Nijmegen completed questionnaires by telephone, with a response rate of 29 of the 30 cases. Only one passenger with symptoms could not be reached, and their questions were answered by one of the other participants of the trip. These data were used to produce an epidemic curve of the dates of symptom onset (Figure). It showed a biphasic pattern with a peak on Day 1 (11 passengers) and a second peak on Day 4 (five passengers). Two patients had two episodes of illness (in the figure only the first onset is shown).

In total, 30 of 40 people became ill during this trip, including one of two drivers and three of four crew members. Those who became ill on Day 1 reported less diarrhoea compared to those who became ill on Day 2 or later. Nine passengers were admitted to a hospital, eight in Germany, and one in the Netherlands on Day 5 of the outbreak.

Norovirus was found in stool samples of two of the eight patients hospitalised in Germany. This diagnosis was later confirmed by the Dutch PHS of Nijmegen, who found norovirus in all of three other tested nonhospitalised passengers (who had not been tested in Germany). All other patients were classified as clinicalepidemiological cases, without further microbiological testing. 25 of 32 people exposed to the water from the boiler in the coach developed symptoms, while four

\section{FIGURE}

Gastroenteritis cases by day of onset of symptoms, coach trip Netherlands-Germany, April $2010(n=30)$

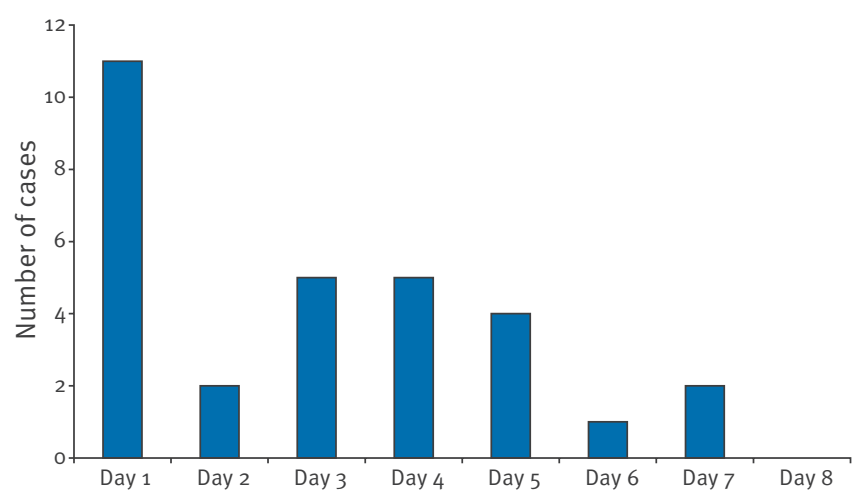


of seven unexposed people became ill, leading to an odds ratio of $\left(25^{*} 3\right) /\left(7^{*} 4\right)=2,68$.

The Table summarises the symptoms, hospital admittance and exposure to boiler water in relation to the day of onset of symptoms of the cases. All people that became ill on Day 1 had taken coffee or tea. Not all the people that became ill later had taken coffee or tea on the first day. Four of the 30 cases experienced nausea only (three of those on Day 1 of the trip), four people had abdominal discomfort and/or vomiting without diarrhoea (two of those on Day 1), and 22 people developed diarrhoea (six of them on Day 1). The symptoms lasted on average three days in the 24 persons for whom the date of recovery was known.

\section{Inspection of the coach}

The first inspection of the water system of the coach by the PHS in Germany revealed nothing unusual. During the second inspection by PHS of Nijmegen a closed hot water boiler was identified as potential source of infection. The driver had put aside a sample of the suspect boiler water that had a faint blue colour. When investigated by the medical officer of the PHS of Nijmegen, the $\mathrm{pH}$ was estimated to be around 4.0 by $\mathrm{pH}$-indicator strip (Merck Acilit). The coach company mentioned that the boiler had recently been treated for calcification with acetic acid, and rinsed afterwards. This could explain the acidic $\mathrm{pH}$, but not the blue colour.

Electrochemical $\mathrm{pH}$ measurement of the water from the boiler revealed a pH of 4.4. Microbiological investigations did not detect Bacillus or Staphylococcus spp. Standard chemical tests for organic compounds were negative. XRF analysis showed a high copper level of $87 \mathrm{mg} / \mathrm{L}$.

\section{Chemical analysis of blood}

\section{from exposed passengers}

Immediately after the high copper level was detected on Day 11 of the outbreak, the PHS of Nijmegen informed the coach company and the passengers by telephone.

\section{TABLE}

Symptoms, hospital admittance and exposure of gastroenteritis cases, by day of onset of symptoms, coach trip Netherlands-Germany, April $2010(n=30)$

\begin{tabular}{|l|c|c|c|}
\hline & $\begin{array}{c}\text { Symptoms } \\
\text { on Day 1 }\end{array}$ & $\begin{array}{c}\text { Symptoms on } \\
\text { Day 2 or later }\end{array}$ & Total \\
\hline Symptoms & 11 & 19 & 30 \\
\hline $\begin{array}{l}\text { Nausea or abdominal } \\
\text { discomfort only }\end{array}$ & 3 & 1 & 4 \\
\hline Vomiting only & 2 & 2 & 4 \\
\hline Diarrhoea only & 0 & 6 & 6 \\
\hline Vomiting and diarrhoea & 6 & 10 & 16 \\
\hline Admitted to hospital & 4 & 5 & $\mathbf{9}$ \\
\hline $\begin{array}{l}\text { Patients exposed to boiler } \\
\text { water/patients with symptoms }\end{array}$ & $11 / 11$ & $14 / 19$ & $\mathbf{2 5 / 3 0}$ \\
\hline
\end{tabular}

All 32 passengers who had taken coffee or tea in the coach received a letter in which they were asked to see their General Practitioner (GP) for precautionary blood tests. The GPs were informed and instructed to test liver function by alanine aminotransferase (ALAT), renal function by creatinine and the copper level in the blood $[10,11]$. Twenty-eight of the exposed passengers were tested.

In one person, tested 19 days after the incident, the blood copper level was found to be slightly elevated (25.9 $\mathrm{\mu mol} / \mathrm{L}$ over reference 13.0-24.0 $\mu \mathrm{mol} / \mathrm{L})$. Liver and renal functions were normal. This person had consumed one cup of coffee on the coach, but did not report any gastrointestinal symptoms during the trip. In four other patients, liver and/or renal functions were abnormal. One patient was known to have a pre-existing renal condition, the other three only had mildly decreased liver or renal function. As previous values of those patients were not known, interpretation was difficult.

\section{Virological testing of stool samples}

In Germany, stool samples taken from two hospitalised cases on Day 3 and 4 were found to be PCR-positive for norovirus. On Day 6 of the outbreak, the Dutch PHS tested stool samples from three other patients with diarrhoea. All three samples showed positive PCR results for Norovirus, and negative results for rotavirus and adenovirus.

\section{Control measures}

The PHS of Hochsauerlandkreis was notified on Day 4 of the outbreak based on the laboratory diagnosis and immediately implemented standard outbreak control measures for norovirus infections in the hotel where the passengers stayed $[12,13]$. These measures included advice on personal hygiene for cases and contacts as well as advice on cleaning and disinfection of the rooms. Among the hotel staff and other guests, none developed symptoms of norovirus infection. The coach driver was advised not to serve drinks prepared from the water supply of the coach during the return journey and to have the system checked after returning home.

The coach company cleaned the bus. To prevent reoccurrence of these problems in their coaches, the PHS advised to adjust the cleaning procedures, replace materials and implement a code of conduct in relation to water refreshment. One month after the outbreak, the PHS of Nijmegen organised an information meeting for all passengers and their relatives. Professionals of the environmental health unit and of the infectious diseases department of the PHS Nijmegen provided information and answered questions.

\section{Discussion and conclusion}

The initial interviews of the cases, performed by the PHS of Hochsauerlandkreis indicated viral gastroenteritis as the likely explanation for the outbreak, which 
was confirmed by the finding of norovirus in two stool samples. Norovirus is a well known cause of gastroenteritis outbreaks during coach trips [3]. A common factor like a common meal before departure was expected [14], but no such source was identified in the interviews. Furthermore, the early onset of symptoms only a few hours after departure, the biphasic pattern of the epidemic curve, and the fact that two people had two episodes of illness made it unlikely that norovirus was the sole explanation for this outbreak [4]. An additional intoxication was suspected.

The National Poisons Information Centre (NVIC) of the RIVM was contacted. Because nausea, vomiting and diarrhoea are very unspecific symptoms and can have many causes, particular toxins could not be identified as possible causes. Because the outbreak seemed food-borne, the Food and Consumer Product Safety Authority (VWA) was contacted. According to the VWA, coffee was unlikely to be the toxic source. They were unable to suggest other possible causes of intoxication. Fortunately, the boiler tank in the coach still contained water, so a sample could be taken for analysis.

The low $\mathrm{pH}$ value of the water and the blue colour were reason to insist on further investigations. Surprisingly, the analyses revealed a high copper level in the boiler water $(87 \mathrm{mg} / \mathrm{L})$. This explained the blue colour but not the acidity of the water. A possible explanation was that the acetic acid, used for decalcification of the boiler, resulted in dissolution of copper from the inside of the boilers' tap system. The acid had probably remained in the boiler for a longer period. The coach company claimed that the boiler was rinsed after the treatment. Apparently, this rinsing was either not performed or not done properly.

Although copper is an essential nutrient involved in haemoglobin formation, excess copper intake can result in adverse health effects [15-17]. Water can be an important source of excess copper intake $[16,17]$. A commonly reported acute adverse health effect after a single oral intake of excess copper is gastrointestinal distress with nausea, vomiting, abdominal pain and diarrhoea as the main symptoms $[11,18]$. These effects occur shortly after exposure and are usually not persistent. Acute gastrointestinal disturbances following a single oral dose of copper in drinking water are reported for copper levels of $30 \mathrm{mg} / \mathrm{L}$ and higher [19].

The copper content in the water supply was high enough to cause single-dose toxicity with the gastrointestinal tract as the primary target organ. The Agency for Toxic Substances and Disease Registry (ATSDR) in Atlanta, United States, has derived a minimal risk level for acute-duration oral exposure (1-14 days) for copper of $0.01 \mathrm{mg} / \mathrm{kg} /$ day [11]. An adult of $70 \mathrm{~kg}$ bodyweight drinking one cup of coffee $(0.25 \mathrm{~L})$ with a copper content of $87 \mathrm{mg} / \mathrm{L}$ by will ingest a single dose of $0.30 \mathrm{mg} /$ $\mathrm{kg}$, 30 times the acute minimum risk level.
The copper intoxication explains the early and acute onset of illness on the first day of the trip, while norovirus infection explains the cases on the later days. We assume that the index patient of the norovirus outbreak vomited as a result of copper intoxication, and thereby accelerated the spread of norovirus. Norovirus is well-known for its transmission by aerosol after vomiting. As far as we know, a norovirus outbreak triggered by vomiting as a result of intoxication has not been described in the literature.

Oral intake of a very high single dose or a high repeated dose of copper is associated with liver and kidney damage, anaemia, immunotoxicity and developmental toxicity. Damage to organs is dependent on genetics, age and copper intake. All exposed passengers were tested for serum copper levels and renal and liver function because of the risk of decreased renal and liver function after copper intoxication at old age $[10,11]$. However, the tests were done at least ten days after the incident, when elevated copper levels could have normalised by then. Nevertheless, a slightly elevated copper level was found in one passenger. Since treatment by chelating therapy is only indicated in acute and severe cases (i.e. complications as haemolytic anaemia, anuria or hepatotoxicity), the patient was only monitored [20]. This person did not report any symptoms at the time of the incident, the liver and renal functions were repeatedly normal and the copper levels returned to normal. Of the other exposed passengers, four people had abnormal liver or renal function; one of them was known to have pre-existing renal dysfunction. The interpretation of liver and renal functions was quite complicated, because they tend to decrease at old age, and baseline values of most of the patients were not available.

This is as far as we know the first report of a combined outbreak of norovirus and intoxication, in our case copper intoxication. This outbreak has demanded a high level of cooperation between the Environmental Health Unit and the Infectious Disease Department of the Dutch PHS, which was a very informative experience. None of the passengers have become critically ill as a result of copper intoxication.

\section{References}

1. Duizer E, Koopmans M. Tracking emerging pathogens: the case of noroviruses. In: Motarjemi Y, Adams M, editors. Boca Raton: Woodhead publishing limited; 2006. p. 77-110.

2. Verhoef L, Boxman IL, Duizer E, Rutjes SA, Vennema H, Friesema IHM, et al. Multiple exposures during a norovirus outbreak on a river-cruise sailing through Europe, 2006. Eurosurveillance 2008;13(24):pii=18899. Available from: http://www.eurosurveillance.org/ViewArticle. aspx?Articleld=18899

3. Visser H, Verhoef L, Schop W, Götz HM. Outbreak investigation in two groups of coach passengers with gastroenteritis returning from Germany to the Netherlands in February 2009. Euro Surveill. 2010;15(28):pii=19615. Available from: http:// www.eurosurveillance.org/ViewArticle.aspx?Articleld $=19615$

4. Glass RI, Parashar UD, Estes MK. Norovirus gastroenteritis. N Engl J Med. 2009;361(18):1776-85.

5. Hoebe CJ, Vennema H, De Roda Husman AM, van Duynhoven YT. Norovirus outbreak among primary schoolchildren who 
had played in a recreational water fountain. J Infect Dis. 2004;189(4):699-705.

6. Thein CC, Trinidad RM, Pavlin BI. A large foodborne outbreak on a small Pacific island. Pac Health Dialog. 2010;16(1):75-80.

7. Thaikruea L, Pataraarechachai J, Savanpunyalert $P$, Naluponjiragul U. An unusual outbreak of food poisoning. Southeast Asian J Trop Med Public Health. 1995;26(1):78-85.

8. Lee SG, Lee SH, Park SW, Suh CI, Jheong WH, Oh S, et al. Standardized positive controls for detection of norovirus by reverse transcription PCR. Virol J. 2011;8:260.

9. Khamrin P, Okame M, Thongprachum A, Nantachit N, Nishimura S, Okitsu S, et al. A single-tube multiplex PCR for rapid detection in feces of 10 viruses causing diarrhea. J Virol Methods. 2011;173(2):390-3.

10. Harvey LJ, Ashton K, Hooper L, Casgrain A, Fairweather-Trait S). Methods of assessment of copper status in humans: a systematic review. Am J Clin Nutr. 2009;89(6):2009S-2024S.

11. Agency for Toxic Substances and Disease Registry (ATSDR). Toxicological profile for Copper. Atlanta: ATSDR; Sep 2004. Available from: http://www.atsdr.cdc.gov/toxprofiles/ tp.asp?id $=206 \&$ tid $=37$

12. Robert Koch Institut (RKI). Noroviren. RKI-Ratgeber für Ärzte. [Noroviruses. RKI guidebook for doctors]. Berlin: RKI; Jul 2008. German. Available from: http://www.rki.de/cln_153/ nn_494558/DE/Content/Infekt/EpidBull/Merkblaetter/ Ratgeber_Noroviren.html\#doc200678bodyText10

13. Sinn G. Hinweise zum Schutz vor Norovirus-Infektionen. [Advice for the protection against norovirus infections]. Epid Bull. 2008:6;45-6. German. Available from: http://www.rki.de/ cln_162/nn_969736/DE/Content/Infekt/EpidBull/Archiv/2008/ 06 _08,templateld=raw,property=publicationFile.pdf/06_08. $\mathrm{pd \overline {f }}$

14. Deneen VC, Hunt JM, Paule CR, James RI, Johnson RG, Raymond MJ, et al. The impact of foodborne calicivirus disease: the Minnesota experience. J Infect Dis. 2000;181 Suppl2:S281-3.

15. Chan S, Gerson B, Subramaniam S. The role of copper, molybdenum, selenium and zinc in nutrition and health. Clin Lab Med. 1998;18(4):673-85.

16. Brewer GJ. Risks of copper and iron toxicity during aging in humans. Chem Res Toxicol. 2010;23(2):319-26.

17. Brewer GJ. The risks of copper toxicity contributing to cognitive decline in the aging population and to Alzheimer's disease. J Am Coll Nutr. 2009;28(3):239-42.

18. United States National Library of Medicine (NLM). Fact Sheet: Hazardous substance data bank (HSDB). Bethesda: NLM; Feb 2011. Available from: http://www.nlm.nih.gov/pubs/ factsheets/hsdbfs.html

19. Committee on Copper in Drinking Water, National Research Council. National Academy of Sciences. Copper in drinking water. Washington: National Academies Press; Apr 2000. ISBN: 9780309069397.

20. Cai L, Li XK, Song Y, Cherian MG. Essentiality, toxicology and chelation therapy of zinc and copper. Curr Med Chem. 2005;12(23):2753-63. 